\title{
FLYING BEYOND BORDERS: INTERMODAL CONSIDERATIONS TO IMPROVE ACCESSIBILITY OF AEGEAN SEA ISLANDS, GREECE USING DISCRETE CHOICE ANALYSIS
}

\author{
Ioulia Poulaki \\ University of the Aegean, Greece \\ Andreas Papatheodorou \\ University of the Aegean, Greece \\ Eleni Kitrinou \\ University of the Aegean, Greece \\ Alexandros Panagiotopoulos \\ Transport \& Railway Engineer
}

\begin{abstract}
Accessibility is of major importance for tourism and trade development in Eastern Aegean Sea islands, Greece. In particular, the island of Chios is heavily dependent on Athens International Airport for both its inbound and outbound tourism. On the other hand, the International Airport of Izmir in Turkey, located much closer to the island, serves several European destinations. Crossing the borders in an intermodal transport context may lead to a substantial air travel alternative for Chios, thus improving its accessibility and potential for tourism development. A discrete choice analysis, based on primary data research regarding travel scenarios from Chios to ten main European airports-destinations, shows the potential for new traffic flows in addition to the existing ones. Airport utility maximization differences observed among various social groups is also noteworthy.
\end{abstract}

Keywords: Airport catchment area, Intermodal transport, discrete choice models, accessibility, travel alternative, utility maximization

Dr Ioulia Poulaki: Laboratory for Tourism Research and Studies, University of the Aegean, Greece. E-mail: i.poulaki@aegean.gr (corresponding author)

Professor Dr Andreas Papatheodorou: Department of Business Administration, University of the Aegean, Greece. E-mail: a.papatheodorou@aegean.gr

Dr Eleni Kitrinou: Department of Shipping, Trade and Transport, University of the Aegean, Greece. Email: e.kitrinou@aegean.gr

Alexandros Panagiotopoulos, Email: alex.panagioto@gmail.com 


\section{INTRODUCTION}

Catchment area analysis refers to the estimation of the geographical area from which a large proportion of an airport's outbound passengers originate, or inbound passengers travel to. Usually, within acceptable travel distances only one airport provides flights to the preferred destination (Poulaki et al, 2013; Kouwenhoven, 2008). However, the evolution in the air transport sector as well as the continuous optimization in surface connections has given people the ability to choose between multiple airports during their travel decision making. Since the deregulation of the airline industry in the USA and Europe, the number of airports providing commercial operations has risen substantially and passengers have a wider choice of airfares and airports than ever before (Papatheodorou, 2002; Koo et al, 2016). Consequently, the size of a catchment area and its dynamics in overlapping with neighbouring catchments, depends on several factors based on airport services (accessibility, frequencies, fares) and air travel demand (time, cost) (Lieshout, 2012). Direct competition between airports has generated more than one air travel alternatives and it is worth investigating how people choose an airport for their travel, i.e. in terms of vicinity or to minimize their general transport cost.

To investigate this point, a study has been undertaken with regards to airport choice between Athens International Airport (ATH) and Izmir Adnan Menderes Airport (ADB), by the inhabitants of the Greek Eastern Aegean Island of Chios. Travel scenarios (total travel time and total travel cost) concerning a roundtrip from Chios to ten (10) main European hubs by air via $A D B$ or via ATH in a questionnaire survey were given to the inhabitants of Chios to establish airport preferences. The results of this investigation provide evidence of the ADB potential to consider an intermodal transportation strategy to expand its catchment area into the Greek Eastern Aegean Islands (Poulaki et al, 2013), since according to Vesperman and Wald (2011) the expansion of an airport's catchment area is to facilitate the ability of airport travellers to use intermodal airport access. This may prove of benefit to both inbound and outbound travellers of Chios especially in an era of cost-cutting around the globe (Papatheodorou and Pappas, 2017).

\section{DISCRETE CHOICE MODELLING}

The air transport industry presents increasing interest for discrete choice models because such models can explain how passengers make decisions at an individual level with regards to air travel. The trade-offs faced by an individual vis-à-vis the various alternatives and the final choice made generate this interest. According to Garrow (2010), the attributes of each 
alternative lead the individual to the final choice which maximizes utility based on priorities that individuals set each time. This is called utility maximization rule through an alternative choice set and may be represented in a function. Factors that affect decision-making are mainly travel time and cost. Additionally, there are others that influence this process such as income, age etc. Thus, a utility function should include all those factors with a respective weight of influence (Kaltsounis and Vythoulkas, 2009).

The simplest discrete choice model widely used is the multinomial logit model (MNL) which is a generalized binary logit model and describes how an individual chooses between three or more discrete alternatives. Similarly to binary logit model, MNL probabilities are derived from the hypothesis that errors follow a Gumbel distribution. To decide which variables will be included in the utility function, a specific procedure, similar to that used in determining the regression models, is applied (Profyllidis, 2008). For each feature, an assessment is made whether the model can explain the final behaviour of the traveller. In this function, the form of regression includes variables that may be generic and/or specific. Generic variables appear in function of the utility of each alternative and their coefficients are the same. Specific ones are variables that appear separately for each option, being displayed in the utility function of that particular option.

\section{RESEARCH METHODOLOGY}

A stated-preference primary research has been undertaken in the island of Chios distributing questionnaires over a two-week period in February 2013, where inhabitants as potential travellers have been called to choose among alternative travel scenarios the one that maximizes their airport utility.

The following map shows the distances between Chios Island and the two airports in question, i.e. Athens International Airport (ATH) and Izmir Adnan Menderes Airport (ADB). At this point it is worth mentioning that most of the island's international tourism (inbound/outbound) concerns domestic/international connecting traffic via ATH. After all, the local market is too small and the Chios airport (JKH) infrastructure is rather limited to sustainably support direct services to international destinations at least on a year-round basis. Interestingly though, an intermodal surface transport solution from Chios to $A D B$ is introduced in this study to illustrate 
that airport's accessibility by the inhabitants of the Greek island and conversely ADB's possible use by inbound tourists too.

Map 1: Accessibility of Izmir Adnan Menderes International Airport from Chios Island

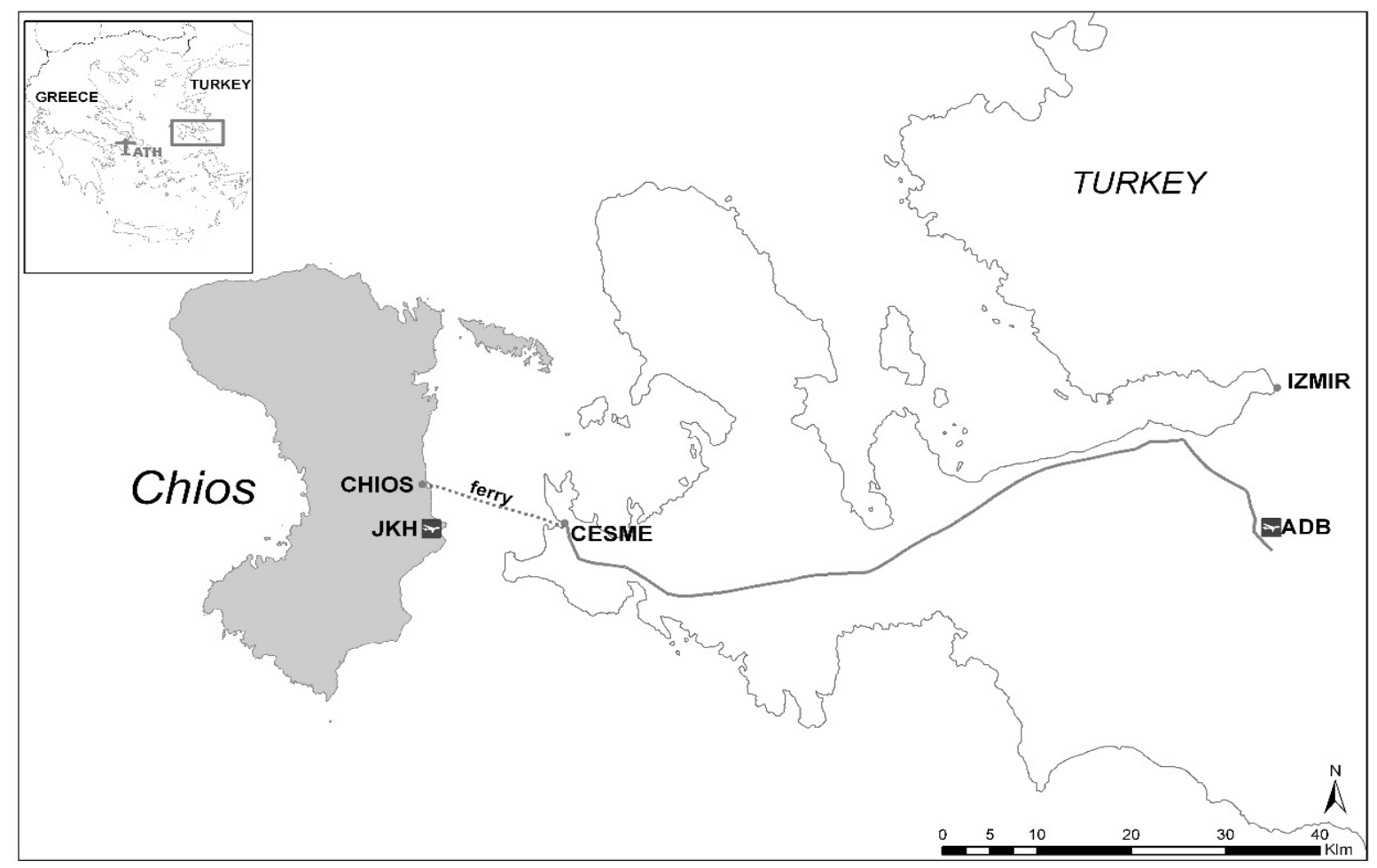

Source: (Poulaki et al, 2013)

Door to door roundtrip travel scenarios have been designed in real time using online booking engines and each alternative scenario includes the optimal solution in terms of travel time and cost (excluding night-stop option). Booking date is the $7^{\text {th }}$ of January 2013 and the travel date concerned the first week of March (1-8/3/2013). Accessibility to ATH is realized by ship from Chios port ( 8 hours \& $60 €$ average fare one way) or by airplane from Chios airport ( $45^{\prime} \& 150$ $180 €$ average fare roundtrip). In addition, accessibility to ADB is realized by an intermodal transport system that includes a Short Sea Shipping Link from Chios port to the port of Cesme and then a shuttle bus to ADB ( 1 hour $40^{\prime} \& 40 €$ average fare roundtrip).

Given travel scenarios refer to travel alternatives using Chios as origin and ten main European cities as destination. This research has the characteristics of a stated preference research as described by Kaltsounis and Vythoulkas (2009) in terms of attributes and particularities which:

- is based on the statements of travellers regarding their response to changes related with their potential travel; 
- each alternative is presented as a bundle of attributes, like travel time, travel cost etc.;

- the analyst builds these hypothetical alternatives to measure the impact of each attribute;

- alternative scenarios given to potential travellers must be understandable and simulate a realistic and possible situation similar to travels already made by them. Participants in the research state their preference choosing among those given scenarios.

To estimate the various utility determinant coefficients, the Biogeme software was used. This software is structured to provide analysts with appropriate tools to test various types of discrete choice models avoiding logarithmic procedure (Kitrinou et al 2010; Bierlair et al, 2009). Variables statistically insignificant are excluded a priori from Biogeme dataset and econometric analysis process. Several tests were undertaken in Biogeme to finalise the number of independent variables which are statistically significant as explanatory to the dependent one and altogether finally formed the econometric model. At this point, it is worth mentioning that repeating the dataset tests and using a general-to-specific approach assures the highest possible validity of the output in dealing with multicollinearity and heteroscedasticity.

The analysis was based on multinomial logit models (MNL) to assess choice probabilities in the case of three alternative travel scenarios, i.e.:

1. Travel from Chios to international destinations via Izmir Adnan Menderes International Airport (ADB - optimized in time and cost)

2. Travel from Chios to international destinations via Athens International Airport Eleftherios Venizelos (ATH - optimized in cost)

3. Travel from Chios to international destinations via Athens International Airport Eleftherios Venizelos (ATH - optimized in time)

Explanatory variables include demographic elements such as age, income, educational level and travel behavioural attributes such as the accompanied status during travelling and intercontinental final destination. Thus, the multinomial logit models include the following variables shown in Table 1. 
Table 1 Variable overview

\begin{tabular}{|c|c|c|c|}
\hline & \multirow{2}{*}{$\begin{array}{l}\text { Variable } \\
\text { Name }\end{array}$} & \multicolumn{2}{|c|}{ Values } \\
\hline & & 1 & 0 \\
\hline 1 & DESTAMS & If the final destination is Amsterdam & Other \\
\hline 2 & DESTBER & If the final destination is Berlin & Other \\
\hline 3 & DESTFRA & If the final destination is Frankfurt & Other \\
\hline 4 & DESTIST & If the final destination is Istanbul & Other \\
\hline 5 & DESTLON & If the final destination is London & Other \\
\hline 6 & DESTMAD & If the final destination is Madrid & Other \\
\hline 7 & DESTMUC & If the final destination is Munich & Other \\
\hline 8 & DESTPAR & If the final destination is Paris & Other \\
\hline 9 & DESTVIE & If the final destination is Vienna & Other \\
\hline 10 & DESTZRH & If the final destination is Zurich & Other \\
\hline 11 & AGE2 & If participant is more than 35 years old & If participant is less than 35 years old \\
\hline 12 & EDUCATION2 & $\begin{array}{l}\text { If the participant holds a tertiary } \\
\text { education degree }\end{array}$ & $\begin{array}{l}\text { If the participant holds a secondary } \\
\text { education degree }\end{array}$ \\
\hline 13 & INCOME2 & $\begin{array}{l}\text { If participant gains more than } 2000 \\
\text { euros per month }\end{array}$ & $\begin{array}{l}\text { If participant gains less than } 2000 \\
\text { euros per month }\end{array}$ \\
\hline 14 & Busnal & Travel alone (not accompanied) & Other \\
\hline 15 & Children & $\begin{array}{l}\text { If the participant doesn't have any } \\
\text { children }\end{array}$ & Other \\
\hline 16 & dum2intldest & If the final destination is the USA & other $^{1}$ \\
\hline 17 & TCIZA & Total travel cost in euros for scenario 1 & \\
\hline 18 & TTIZA & $\begin{array}{l}\text { Total travel time in hours for scenario } \\
1\end{array}$ & \\
\hline 19 & TCATA & Total travel cost in euros for scenario 2 & \\
\hline 20 & TTATA & $\begin{array}{l}\text { Total travel time in hours for scenario } \\
2\end{array}$ & \\
\hline 21 & TCATB & Total travel cost in euros for scenario 3 & \\
\hline 22 & ТТАТВ & $\begin{array}{l}\text { Total travel time in hours for scenario } \\
3\end{array}$ & \\
\hline
\end{tabular}

${ }^{1}$ Participants who declared that have already realized a travel from Chios to international destination via ADB 


\section{RESULTS AND OUTPUT INTERPRETATION}

Table 2 two summarizes the main aggregate model statistics:

Table 2 Aggregate Model Statistics

\begin{tabular}{|c|c|}
\hline Number of observations & 2196 \\
\hline Number of individuals & 2196 \\
\hline Null log-likelihood & -2168.868 \\
\hline Init log-likelihood & -2168.868 \\
\hline Final log-likelihood & -1015.478 \\
\hline Likelihood ratio test & 2306.780 \\
\hline $\mathrm{R}^{2}$ & 0.532 \\
\hline Adjusted $\mathrm{R}^{2}$ & 0.523 \\
\hline
\end{tabular}

Tables 3, 4 and 5 report the estimated coefficients for scenarios 1, 2 and 3 respectively

Table 3 Utility coefficients for scenario 1

\begin{tabular}{|c|c|c|c|}
\hline Variable Name & Coefficient & t-statistic & $p$-value \\
\hline Constant (for scenario 1) & 0.653 & 1.78 & 0.07 \\
\hline TC (generic) & -0.00928 & -6.76 & 0.00 \\
\hline TT (generic) & -0.0867 & -5.53 & 0.00 \\
\hline DESTAMS & 0.00644 & 1.48 & 0.14 \\
\hline DESTBER & -0.00256 & -0.68 & 0.50 \\
\hline DESTFRA & -0.0568 & -0.29 & 0.77 \\
\hline DESTIST & 0.0155 & 0.10 & 0.92 \\
\hline DESTLON & 0.145 & 1.98 & 0.05 \\
\hline DESTMAD & 0.0281 & 0.20 & 0.84 \\
\hline DESTMUC & 0.000159 & 0.05 & 0.96 \\
\hline DESTPAR & 0.0612 & 0.44 & 0.66 \\
\hline DESTVIE & -0.0641 & -0.49 & 0.62 \\
\hline DESTZRH & -0.0241 & -0.58 & 0.56 \\
\hline EDUCATION2 & 0.207 & 1.65 & 0.10 \\
\hline
\end{tabular}

Having Table 3 in mind, the utility function in the case of Scenario 1 may be modelled as follows: 


$$
\begin{aligned}
U_{I Z}=0.653 & +0.145 * \text { DESTLON }+0.000159 * \text { DESTMUC }+0.00644 * \text { DESTAMS }-0.00256 \\
& * \text { DESTBER }+0.0612 * \text { DESTPAR }-0.0641 * \text { DESTVIE }-0.0568 * \text { DESTFRA } \\
& +0.0155 * \text { DESTIST }+0.0281 * \text { DESTMAD }-0.0241 * \text { DESTZRH }+0.207 \\
& * \text { EDUCATION }-0.0867 * \text { TTIZA }-0.00928 * \text { TCIZA }
\end{aligned}
$$

Table 4 Utility coefficients for scenario 2

\begin{tabular}{|c|c|c|c|}
\hline Variable Name & Coefficient & t-statistic & $p$-value \\
\hline Constant (for scenario 2) & -0.377 & -1.26 & 0.21 \\
\hline TC (generic) & -0.00928 & -6.76 & 0.00 \\
\hline TT (generic) & -0.0867 & -5.53 & 0.00 \\
\hline AGE2 & 1.30 & 10.29 & 0.00 \\
\hline busnal & 0.174 & 1.07 & 0.29 \\
\hline children & 0.0189 & 0.88 & 0.38 \\
\hline
\end{tabular}

Having Table 4 in mind, the utility function in the case of Scenario 2 may be modelled as follows:

$$
\begin{aligned}
U_{A 1}=-0,377 & -0,0867 * \text { TT ATA }-0,00928 * \text { TCATA }+0,0189 * \text { children }+0,174 * \text { busnal } \\
& +1,30 * \text { AGE } 2
\end{aligned}
$$

Table 5 Utility coefficients for scenario 3

\begin{tabular}{|c|c|c|c|}
\hline Variable Name & Coefficient & $t$-statistic & $p$-value \\
\hline Constant (fixed for scenario 3) & 0 (by default) & Default & default \\
\hline TC (generic) & -0.00928 & -6.76 & 0.00 \\
\hline TT (generic) & -0.0867 & -5.53 & 0.00 \\
\hline INCOME2 & -0.259 & -0.71 & 0.47 \\
\hline dum2intldest & -0.0703 & -0.07 & 0.94 \\
\hline
\end{tabular}

Having Table 5 in mind, the utility function in the case of Scenario 3 may be modelled as follows:

$$
U_{A 2}=-0,0867 * \text { TTATB }-0,00928 * \text { TCATB }-0,259 * \text { INCOME2 - 0,0703*dum2intldest }
$$

Before interpreting the output of the econometric analysis, it is worth mentioning that after several tests we ended up in the advanced full generic version of processing the variables. One reason is that third travel scenario was available only for the 6 destinations, so missing 
data of the remaining four influenced the specific process output. Another one is that utility coefficients presented optimized statistic indexes in the case of the generic process.

Constants in utility functions declare the willingness of the participants, while variable coefficients declare the choice probability. Constant in scenario 3 is 0 by default. Travel time and cost factors as explanatory variables are included each time in the function of the corresponding alternative choice scenario having the same beta coefficient in the context of the generic data process. Furthermore, Biogeme tends to place variables in the functions where they present statistical significance. Additionally, interpreting variables are included in the corresponding functions even though they do not seem to present statistical significance. Having the above in mind, the results may be interpreted as follows:

Scenario 1: This is more likely to be chosen by individuals of higher educational level. Especially air travel to London, Munich, Paris, Istanbul, Amsterdam and Madrid seems to be preferred via $A D B$ as the coefficients for those destinations have a positive sign.

Scenario 2: This is more likely to be chosen by individuals who are not attracted by scenario 1. More specifically, these are individuals without children, older in age and not accompanied while travelling for business purposes.

Scenario 3: This is more likely to be chosen by individuals with a higher monthly income and by those whose final destination is the USA.

The fact that all destinations are placed by the model in the utility function of scenario 1 shows that most of the participants chose to travel internationally from Chios via ADB. Furthermore, econometric analysis gives more information with regards to the individual profile for alternative choices that maximize utility of each potential travel.

\section{CONCLUSIONS}

Econometric analysis using discrete choice modelling proves that an airport catchment area is not stable and may experience radical transforms in case of a change in significant determinant factors of choice and decision-making. By adopting an intermodal transport strategy, an airport may improve its accessibility and attract passengers from other airports of the wider region even from the other side of the borders; the key is utility maximization. Despite the known geopolitical complexities between Greece and Turkey, the present case study reveals that 
economics (at least in a stated-preference individual context) may play a more important role. In any case, undertaking a similar research exercise for inbound travellers is necessary; this is the only way to validate that in addition to outbound, inbound tourists to Chios are also interested in visiting the island via ADB. Still, the present study implicitly argues that this may be a valid assumption to make. Finally, replicating the study in a different geographical region can be very interesting and valuable to further support the dynamics of an airport's catchment area especially when its level of services and accessibility from neighbouring border regions and countries improves.

\section{REFERENCES}

1. Bierlaire M., Fetiarison, M. (2009) Estimation of discrete choice models: extending Biogeme, STRANSPOR, Ecole Polytechnique Federale de Lausanne

2. Garrow, L. (2010) Discrete Choice Modelling and Air Travel Demand: Theory and Applications, Ashgate, USA, 15-25 \& 33-47

3. Kaltsounis, A., Vythoulkas, P., (2009) Distribution in transport means - Discrete Choice Analysis, notes for Transport Systems course in Lab of Transport Engineering, Department of Surveying Engineering, NTUA (in greek)

4. Kitrinou E., Polydoropoulou, A., Bolduc, D. (2010), Development of Integrated Choice and Latent Variable (ICLV) Models for the Residential Relocation Decision in Island Areas, in Stephane Hess, Andrew Daly (ed.) Choice Modelling: The State-of-the-art and The State-of-practice (Default Book Series, Volume ), 593 - 618

5. Koo, T., Halpern, N., Papatheodorou, A., Graham, A., Arvanitis, P. (2016) Air Transport Liberalisation and Airport Dependency: Developing a Composite Index, Journal of Transport Geography, 50: 83-93.

6. Kouwenhoven, M. (2008) The Role of Accessibility in Passengers Choice of Airports. Discussion paper No. 2008-14, Prepared for the Round Table of on Airline Competition (October), Systems of Airports and Intermodal Connections, OECD/ITF.

7. Lieshout, R. (2012) Measuring the size of an airport's catchment area. Journal of Transport Geography, 25, 27-34.

8. Papatheodorou, A. (2002) Civil Aviation Regimes and Leisure Tourism in Europe. Journal of Air Transport Management, 8(6): 381-388.

9. Papatheodorou, A. and Pappas, N. (2017) Economic Recession, Job Vulnerability and Tourism Decision-Making: A Qualitative Comparative Analysis, Journal of Travel Research, 56(5): 663-677.

10. Poulaki, I., Papatheodorou, A., Stergiou, D. (2013) Expanding cross border airport catchment area using intermodality: The case of Adnan Menderes International Airport of Izmir, Journal: Tourism Today, Vol: Fall 2013, 48-60

11. Profyllides, V., (2008) Transport Economics, Athens: Papasotiriou (in greek)

12. Vesperman, J. and Wald, A. (2011) Intermodal integration in air transportation: Status quo, motives and future developments. Journal of Transport Geography, 19, 1187-1197. 